\title{
Assessing the Prevalence of Recurrent Neck and Shoulder Pain in Korean High School Male Students: A Cross-sectional Observational Study
}

St. Mark's School, U.S.A., *Department of Anesthesiology and Pain Medicine, Soonchunhyang University Seoul Hospital, Seoul,

${ }^{\dagger}$ Department of Anesthesiology and Pain Medicine, Soonchunhyang University Bucheon Hospital, Bucheon,

${ }^{\ddagger}$ Department of Anesthesiology and Pain Medicine, Soonchunhyang University Cheonan Hospital, Cheonan,

${ }^{\S}$ Department of Pain Medicine, Godoil Hospital, Seoul, Korea

Min Jung Koh, Sun Young Park, MD*, Young Sun Woo, RN ${ }^{\dagger}$, Sung Hyun Kang, MD*, Sang Hoon Park, MD*, Hye Jung Chun, $\mathrm{MD}^{\ddagger}$, and Eun Jung Park, $\mathrm{MD}^{\S}$

\section{Background:}

Neck and shoulder pain (NSP) is fairly common in adolescents, which is associated with a high prevalence of NSP found during adulthood as well; therefore, its significance during adolescence should not be underestimated. We surveyed the prevalence of recurrent NSP, lifestyle, and risk factors in Korean high school students, and examined the influence of recurrent NSP on the quality of life.

\section{Methods:}

Nine hundred thirty one male students (16-19 years old) from two academic high schools in Seoul were included in this study. The survey consisted of a questionnaire to assess the prevalence of recurrent NSP, with questions regarding having an occurrence more than once a week, characteristics of NSP, activity and lifestyle of the students, and the risk factors for recurrent NSP. A 36-item Short Form questionnaire was also examined.

\section{Results:}

We found that $44.3 \%$ of the high school students surveyed had recurrent NSP (more than once a week) and the overall prevalence of NSP was $79.1 \%$. The average sitting time was $10.2 \pm 2.7 \mathrm{~h} /$ day. $59.0 \%$ did not sit straight, $14.7 \%$ used assisting devices during reading, and $11.9 \%$ answered that they stretched regularly. Found from their self assessed health, frequent fatigue and frequent depressed mood presented significant associations with the higher prevalence of recurrent NSP.

\section{Conclusions:}

Korean high school students had a high prevalence of recurrent NSP. Clinical attention is needed for the prevention and resolution of recurrent NSP found in high school students. (Korean J Pain 2012; 25: 161-167)

\section{Key Words:}

associated factors, neck pain, prevalence, shoulder pain, students.

Received March 15, 2012. Revised June 5, 2012. Accepted June 7, 2012.

Correspondence to: Sun Young Park, MD

Department of Anesthesiology and Pain Medicine, Soonchunhyang University Seoul Hospital, 657, Hannam-dong, Yongsan-gu, Seoul 140-743, Korea

Tel: +82-2-709-9291, Fax: +82-2-790-0394, E-mail: sunnypark97@gmail.com

() This is an open-access article distributed under the terms of the Creative Commons Attribution Non-Commercial License (http:// creativecommons.org/licenses/by-nc/3.0/), which permits unrestricted non-commercial use, distribution, and reproduction in any medium, provided the original work is properly cited.

Copyright (c) The Korean Pain Society, 2012 


\section{INTRODUCTION}

Neck and shoulder pain (NSP) is a relatively mild musculoskeletal condition, but it is common enough to be a public health problem that is associated with significant disability [1,2], while also having an economic impact [3] to the general population. The reported lifetime of the prevalence of neck pain in adults ranges from $20-70 \%$, which increases with age up to 60-70 years old [1,4-6]. Symptoms are also fairly common in adolescents, so it has become an increasing health problem [7]. In a longitudinal study, NSP during adolescence was associated with a high prevalence for NSP during adulthood [8]; therefore, its significance during adolescence should not be underestimated. However, such epidemiologic data on adolescents' NSP have been scarcely published in Korea.

Common causes of NSP include muscle \& ligamentous injury, or NSP may result from degenerative changes of the cervical facet joints and discs while also forming as a result of irritation, inflammation, and the mechanical distortion of the cervical nerve roots and spinal cord [9]. Cervical degenerative changes or mechanical distortions of the nerve are unlikely in adolescence; NSP in adolescents may result from the injury of muscles and ligaments found in the cervical portion. These injuries can result from factors related to posture, poor ergonomics, stress, injury, and chronic muscle fatigue [9]. Presumably, NSP is a consequence of a prolonged, inappropriate static position that results in minor injuries of the muscles and ligaments. Therefore, in adolescent NSP, activity and lifestyle patterns are important. Korean adolescents spend much of their time sitting and have relatively low physical activity. Due to this, it is suspected that NSP is more prevalent and is presenting itself as a recurrent pattern in Korean adolescents.

In this study, we surveyed the prevalence of recurrent NSP through lifestyle and risk factors for recurrent NSP in Korean high school students, while also examining the influence of recurrent NSP on the quality of life as measured through a 36-item Short Form (SF-36) questionnaire.

\section{MATERIALS AND METHODS}

The institutional review board approved the protocols for this study. In February, 2012, 931 male students (16-19 years old), from two academic high schools in Seoul, were included in this study. The survey consisted of a questionnaire which was delivered to students at the schools, and that included site-specific questions of pain for different areas of the body; head, neck and shoulder, elbow, wrist, back, groin, knee, and foot. Among them, NSP was linked to a six-level frequency classification system that recorded the data for the previous 6 months (never, once in 6 months, once a month, once a week, once every 2-3 days, and almost daily), which also included their duration. Recurrent NSP was defined as NSP that occurred at least once a week. The subjective recurrent NSP-induced effect on schoolwork was calculated using the following statements answered by a four-point scale: (1) I experience NSP, but have no difficulty in school due to NSP; (2) NSP bothers me during physical education class; (3) I have difficulty sitting during lessons due to NSP; and (4) NSP bothers me, so I cannot study at all. The use of sick leave and painkillers due to NSP were determined using yes/no questions.

To assess the activity and lifestyle of the students, we surveyed the duration of sleep, the duration that students sat during school and at home daily, their sitting postures during lessons, the use of an assisting device for reading (e.g., a bookstand or armrest), and whether they stretched regularly. The questionnaire included questions regarding the use of cell phones for instance, the duration of continuous use, duration of average daily use, and the posture during use, such as head flexion. In addition, there were questions regarding leisure activities and exercise, which focused on the intensity of physical activity on a threepoint scale, exercise frequency on a four-point scale, and exercise intensity measured on a two-point scale by asking if exercise caused heavy breathing and sweating.

For the evaluation of potential risk factors, the history of accidents was questioned. An overall measure of selfreported health on a five-point scale was included with the question, 'Would you say that, compared with others of the same age, your health is generally: excellent, good, fair, poor, or very poor?' Symptoms of fatigue, mental distress, sleep quality, and depressed moods were measured by the symptom's presence, along with frequency questions, and with responses ranging from 1-3 (1: never, 2: seldom, 3: frequently). Students also filled out a validated Korean version of the $\mathrm{SF}-36$ questionnaire [10], which measures self-reported health and the quality of life.

The primary outcome variable was the prevalence of recurrent NSP, more than once a week, in the high school 
students. The secondary outcome variables were the characteristics of NSP, activity and lifestyle of the students, the risk factors for recurrent NSP, and the results of the 36-item Short Form (SF-36) questionnaire.

The variables are shown as percentages $(95 \% \mathrm{CI})$, mean, standard deviation (SD), and absolute values. The association of recurrent NSP and other variables was analyzed by the chi-square test or the Student's t-test. Tests for a linear trend across categories were performed using

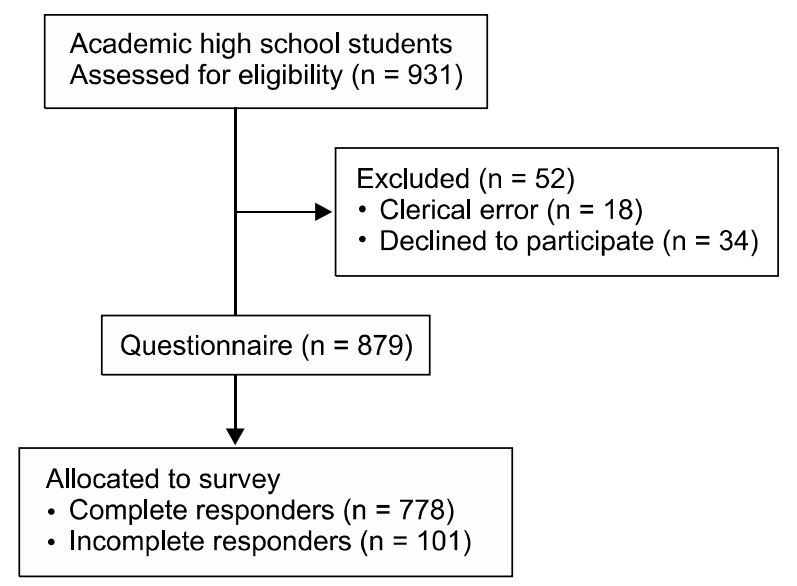

Fig. 1. Study design. a linear by linear association for ordinal variables. We analyzed the odds ratio with a $95 \%$ confidence interval for the potential risk factors in predicting the likelihood for recurrent NSP by using logistic regression analysis. The influence of recurrent NSP on the quality of life, as measured by the SF-36, was assessed using the Student's t-test. The statistical analysis was performed with SPSS 12.0 (SPSS Inc., Chicago, IL, USA). $P$ value $<0.05$ (2-tailed) was considered to be statistically significant.

\section{RESULTS}

Of the 931 students surveyed, 52 students were excluded; of these, 18 had missing questionnaire data due to clerical errors, and 34 refused to participate (Fig. 1). A total of 879 students completed the questionnaire, the mean age was $17.2 \pm 0.5$ years old, mean weight was $66.6 \pm$ $11.0 \mathrm{~kg}$, and the mean height was $175.2 \pm 6.7 \mathrm{~cm}$.

Recurrent NSP was reported by $44.3 \%$ (95\% CI, 40.847.7) of the students. The overall prevalence of NSP was 79.1\% (95\% CI, 76.5-81.7) during the previous 6 months (Table 1), and $94.3 \%$ of those students reported that their NSP persisted for less than 1 week; only $0.7 \%$ of the students reported the persistence of NSP for more than 3

Table 1. The Characteristics of NSP in the Previous 6 Months

\begin{tabular}{|c|c|c|}
\hline Characteristics & Numbers & Percentage $(\mathrm{Cl})$ \\
\hline \multicolumn{3}{|l|}{ Frequency $(n=879)$} \\
\hline Never & 183 & $21.7 \%(19.2-24.5)$ \\
\hline Once in 6 months & 153 & $18.0 \%(15.4-20.7)$ \\
\hline Once a month & 123 & $14.5 \%(12.1-16.7)$ \\
\hline Once a week & 161 & $19.0 \%(16.4-21.6)$ \\
\hline Once every $2-3$ days & 159 & $18.7 \%(16.3-21.4)$ \\
\hline Almost daily & 69 & $8.1 \%(6.4-10.0)$ \\
\hline \multicolumn{3}{|l|}{ Duration $(n=695)$} \\
\hline Several hours & 332 & $47.9 \%(43.8-52.1)$ \\
\hline$\sim$ less than one day & 122 & $17.5 \%(14.5-20.5)$ \\
\hline ress than one week & 62 & $8.9 \%(6.8-11.2)$ \\
\hline$\sim$ less than one month & 14 & $2.0 \%(1.0-3.1)$ \\
\hline 〜ess than three month & 8 & $1.2 \%(0.3-2.1)$ \\
\hline More than three month & 5 & $0.7 \%(0.2-1.3)$ \\
\hline \multicolumn{3}{|l|}{ Intensity $(n=695)$} \\
\hline Have no difficulty in school due to NSP & 42 & $6.0 \%(4.4-7.7)$ \\
\hline NSP bothers me during physical education class & 112 & $16.1 \%(13.6-18.8)$ \\
\hline I have difficulty sitting during lessons due to NSP & 259 & $37.3 \%(34.0-40.9)$ \\
\hline NSP bothers me, so I cannot study at all & 281 & $40.5 \%(36.8-43.8)$ \\
\hline
\end{tabular}

Numbers do not always add to 879 or 695 because of missing data on factors. NSP: neck and shoulder pain. 
months. Of the students, 22.1\% (95\% CI, 19.2-25.1) answered that they had difficulties in studying because of their NSP (subjective NSP-induced effect on the schoolwork index was 3-4/4), while 40.5\% (95\% CI, 37.1-44.1) reported no disabilities (subjective NSP-induced effect on the schoolwork index was 1/4). The use of sick leave and painkillers due to NSP were reported as 6.3 and $4.8 \%$, respectively.

The average duration of sleep was $6.1 \pm 1.2 \mathrm{~h} /$ day, the average sitting time was $10.2 \pm 2.7 \mathrm{~h} /$ day. 59.0\% (95\% CI, 55.6-62.2) answered that they did not sit straight, $14.7 \%$ (95\% CI, 12.1-17.8) used assisting devices during reading, and $11.9 \%(95 \% \mathrm{CI}, 9.5-14.7)$ answered that they stretched regularly. Of the students, 87.9\% (95\% CI, 85.190.3) had their own cell phone. Continuous cell phone usage ranged from $5.7 \pm 20.5$ to $40.3 \pm 93.2 \mathrm{~min}$, with a total use of $71.4 \mathrm{~min} /$ day. A total of $76.2 \%$ (95\% CI, 72.6-79.4) answered that they maintained a flexed head

Table 2. The Prevalence of Recurrent NSP in the Previous 6 Months, Stratified by Variable Factors

\begin{tabular}{|c|c|c|c|c|c|}
\hline Factor & Category & $\begin{array}{c}\text { Number of } \\
\text { students (rNSP/total) }\end{array}$ & Prevalence of rNSP & Adjusted OR (95\% Cl) & $P$ \\
\hline \multirow[t]{2}{*}{ BMI } & $<25$ & $329 / 740$ & $44.40 \%$ & 1 & 0.977 \\
\hline & $\geq 25$ & $47 / 105$ & $44.70 \%$ & $0.98(0.60-1.59)$ & 0.954 \\
\hline $\begin{array}{l}\text { Number of other } \\
\text { musculoskeletal pains }\end{array}$ & $0-8$ & $389 / 877$ & & & 0.896 \\
\hline \multirow[t]{2}{*}{ History of accident } & No & $321 / 720$ & $44.50 \%$ & 1 & 0.821 \\
\hline & Yes & $55 / 123$ & $44.70 \%$ & $0.90(0.56-1.41)$ & 0.635 \\
\hline \multirow[t]{5}{*}{ Health* } & Excellent & $74 / 212$ & $34.90 \%$ & 1 & 0.035 \\
\hline & Good & $113 / 292$ & $38.60 \%$ & $1.06(0.69-1.63)$ & 0.766 \\
\hline & Fair & $108 / 213$ & $50.70 \%$ & $1.44(0.93-2.32)$ & 0.124 \\
\hline & Poor & $52 / 86$ & $60.40 \%$ & $2.09(1.13-3.87)$ & 0.019 \\
\hline & Very poor & $13 / 17$ & $76.40 \%$ & $4.59(1.13-18.7)$ & 0.033 \\
\hline \multirow[t]{3}{*}{ Fatigue } & Never & $3 / 24$ & $2.40 \%$ & 1 & 0.000 \\
\hline & Seldom & $177 / 492$ & $35.90 \%$ & $2.71(0.77-9.59)$ & 0.120 \\
\hline & Frequently & $207 / 357$ & $57.90 \%$ & $6.22(1.73-22.3)$ & 0.005 \\
\hline \multirow[t]{3}{*}{ Mental distress } & Mild & $31 / 94$ & $32.90 \%$ & 1 & 0.410 \\
\hline & Moderate & $264 / 598$ & $44.10 \%$ & $1.01(0.57-1.77)$ & 0.971 \\
\hline & Severe & $90 / 179$ & $50.20 \%$ & $0.75(0.38-1.49)$ & 0.414 \\
\hline \multirow[t]{4}{*}{ Sleep quality } & Excellent & $64 / 177$ & $36.10 \%$ & 1 & 0.992 \\
\hline & Good & $166 / 387$ & $42.80 \%$ & $1.01(0.66-1.56)$ & 0.935 \\
\hline & Fair & $129 / 263$ & $49.00 \%$ & $1.06(0.66-1.69)$ & 0.792 \\
\hline & Poor & $28 / 45$ & $62.20 \%$ & $1.08(0.48-2.47)$ & 0.841 \\
\hline \multirow[t]{3}{*}{ Depressed mood } & Never & $55 / 157$ & $3.10 \%$ & 1 & 0.058 \\
\hline & Seldom & $247 / 571$ & $43.20 \%$ & $1.19(0.76-1.86)$ & 0.430 \\
\hline & Frequently & $83 / 143$ & $58.00 \%$ & $1.98(1.08-3.61)$ & 0.025 \\
\hline \multirow[t]{2}{*}{ Sitting position } & Good & $134 / 350$ & $38.30 \%$ & 1 & 0.002 \\
\hline & Poor & $245 / 504$ & $48.60 \%$ & $1.37(0.98-1.90)$ & 0.059 \\
\hline \multirow[t]{2}{*}{ Assisting device } & Yes & $52 / 109$ & $47.70 \%$ & 1 & 0.668 \\
\hline & No & $331 / 758$ & $43.60 \%$ & $0.84(0.52-1.35)$ & 0.485 \\
\hline \multirow[t]{3}{*}{ Activity } & Good & $106 / 269$ & $39.40 \%$ & 1 & 0.205 \\
\hline & Fair & $178 / 376$ & $47.30 \%$ & $1.33(0.86-2.06)$ & 0.199 \\
\hline & Poor & $104 / 231$ & $45.00 \%$ & $0.96(0.56-1.65)$ & 0.907 \\
\hline \multirow[t]{4}{*}{ Exercise } & Daily & $55 / 130$ & $42.30 \%$ & 1 & 0.888 \\
\hline & Frequently & $103 / 240$ & $42.90 \%$ & $0.83(0.49-1.41)$ & 0.507 \\
\hline & Seldom & $184 / 400$ & $46.00 \%$ & $0.80(0.46-1.40)$ & 0.438 \\
\hline & Never & $44 / 99$ & $44.40 \%$ & $0.83(0.39-1.76)$ & 0.641 \\
\hline
\end{tabular}

Numbers do not always add to 879 because of missing data on factors. rNSP: recurrent neck and shoulder pain. *Indicate a significant linear trend $(P<0.05)$ between recurrent NSP and the variables. 
Table 3. Health-related Quality of Life as Measured with SF-36 Among Students Reporting and Not Reporting Recurrent NSP

\begin{tabular}{lcccc}
\multicolumn{1}{c}{ Parameters } & No rNSP & rNSP & Difference $(95 \% \mathrm{Cl})$ & $P$ \\
\hline Physical functioning & $72.4 \pm 35.0$ & $76.5 \pm 25.3$ & $-4.1(-12.1-3.9)$ & 0.317 \\
Role physical & $64.4 \pm 36.2$ & $70.7 \pm 30.8$ & $-6.2(-14.9-2.4)$ & 0.157 \\
Body pain & $85.4 \pm 16.2$ & $74.3 \pm 20.3$ & $11.1(6.6-15.5)$ & 0.000 \\
General health & $62.3 \pm 17.3$ & $55.1 \pm 19.6$ & $7.1(2.6-11.7)$ & 0.002 \\
Vitality & $56.3 \pm 14.8$ & $52.0 \pm 14.1$ & $4.3(0.6-7.9)$ & 0.021 \\
Social functioning & $74.5 \pm 23.3$ & $73.2 \pm 24.5$ & $1.2(-4.7-7.2)$ & 0.683 \\
Role emotional & $63.1 \pm 37.8$ & $70.2 \pm 33.3$ & $-7.1(-16.2-2.0)$ & 0.127 \\
Mental health & $54.9 \pm 16.3$ & $52.2 \pm 15.2$ & $2.7(-1.2-6.7)$ & 0.183 \\
Physical component score & $68.0 \pm 15.1$ & $65.6 \pm 13.7$ & $2.4(-1.2-6.1)$ & 0.191 \\
Mental component score & $62.1 \pm 15.5$ & $60.5 \pm 13.6$ & $1.6(-2.0-5.4)$ & 0.385 \\
SF36 total score & $66.7 \pm 15.9$ & $65.5 \pm 13.4$ & $1.1(-2.6-4.9)$ & 0.541 \\
\hline
\end{tabular}

rNSP: recurrent neck and shoulder pain.

position. Additionally, 26.3\% (95\% CI, 23.7-29.2) of the students had poor activity. 42.6\% (95\% CI, 39.1-46.9) answered that they take part in physical exercise frequently, while among them, $76.2 \%$ (95\% CI, 72.6-79.4) exercise until they experience panting and sweating.

We analyzed the odds ratio with a $95 \%$ confidence interval for variable factors known as risk factors of NSP (Table 2). Although a number of other musculoskeletal pains were significant risk factors, there were no linear trends $(P=0.06)$. However, there were significant linear trends of the increase in risks across the five categories of self assessed health $(P<0.01)$. 11.7\% (95\% CI, 9.514.5) of the students had low self-reported health (poor or very poor). Frequent fatigue and frequent depressed moods presented significant associations with the higher prevalence of recurrent NSP. Except for general health, body pain and vitality, all items in the SF-36 were not affected in the recurrent NSP (Table 3).

\section{DISCUSSION}

We found that $44.3 \%$ of the high school students studied had recurrent NSP (more than once a week). The overall prevalence of NSP was $79.1 \%$ with most of the occurrences of NSP persisting for less than 1 week, while sick leave and painkiller use due to the NSP were uncommon. Therefore, we could predict that the NSP experienced by high school students is not usually chronic or severe. Many students had no difficulty studying because of their recurrent NSP, and the Health-related quality of life, as measured by $\mathrm{SF}-36$, was not affected with the recurrent NSP.
In the study of Jung et al. [11], the prevalence of NSP in Korean high school students was $82.9 \%$ whereas weekly NSP was $33.4 \%$. The prevalence of adolescent weekly NSP is $10-20 \%$ in Europe $[8,12,13]$. In this present study, the results were similar to that of Jung et al. [11]; this confirms that recurrent NSP is common and its prevalence is higher among high school students in Korea than in Europe. This is contrary to the adult studies, which suggested a lower reported prevalence in Asian populations [6,14].

Psychosocial factors affect the incidence of NSP. Jung et al. [11] reported that moderate stress and poor self-assessed physical conditions were associated with a higher risk of NSP in male students. Siivola et al. [8] showed that psychosomatic symptoms, fatigue, and sleeping difficulties during adolescence were associated with a higher prevalence of NSP in adulthood. In addition, poor self-assessed health and psychological distress are associated with increased incidences of neck pain [14]. In our study, there was a linear trend for increasing risks across the five categories of self assessed health. Additionally, frequent fatigue and frequent depressed moods presented significant associations with a higher prevalence of recurrent NSP. Based on these results, NSP could be a psychosomatic symptom.

However, we should not focus only on these factors or underestimate the effects of nociceptive and musculoskeletal mechanical factors when dealing with NSP. We speculate that NSP also reflects the nature and the site of injury in high school students. Croft et al. [14] suggested that psychological distress or poor physical fitness are likely to be numerically more important in influencing the 
total burden of adult neck pain. For those who have had a neck injury however, it would seem that the injury itself is the biggest single influence on the likelihood of developing a recurrence of NSP. Cervical strains and sprains are the most common causes of NSP, which can result from poor posture, sleeping habits, chronic muscle fatigue, and trauma [9]. Korean high school students spend a lot of time sitting. In this survey, the average sitting time was 10 $\mathrm{h} /$ day, and many students reported that they maintained poor sitting positions during their lessons. In addition, only some of the students used an assisting device while reading or stretched regularly. Most of the students had their own cell phones and used them continuously for up to 40 min, mostly in poor ergonomic positions. Repetitive and prolonged static postures have been found to initiate or exacerbate NSP [15-17]. Therefore, these issues in Korean students might be important factors for the high prevalence of recurrent NSP in this age group. Although we could not find a correlation in this study, we need to be cautious about these issues.

There were several limitations to this study. First, we could not confirm the risk factors of the high prevalence of recurrent NSP. Because this was a cross-sectional study and not a longitudinal or controlled study, the cause and effect were difficult to establish. Therefore, we simply presented the conditions and the prevalence of recurrent NSP in the students. Second, the data was self-reported so we could not exclude recall bias. Third, this study was conducted in only two schools in Seoul, Korea, and it is unlikely that this could be representative of all Korean high school students. In addition, all of the participants were male, although symptoms have been found more frequently among females than males, which is analogous to the adult population $[14,18]$.

In conclusion, Korean high school students had a high prevalence of recurrent NSP. We need further clinical attention for the high prevalence of recurrent NSP and the high school students need the education for prevention and resolution of recurrent NSP.

\section{REFERENCES}

1. Côté P, Cassidy JD, Carroll L. The Saskatchewan Health and Back Pain Survey. The prevalence of neck pain and related disability in Saskatchewan adults. Spine (Phila Pa 1976)
1998; 23: 1689-98.

2. Picavet HS, Schouten JS. Musculoskeletal pain in the Netherlands: prevalences, consequences and risk groups, the DMC(3)-study. Pain 2003; 102: 167-78.

3. Meerding WJ, Bonneux L, Polder JJ, Koopmanschap MA, van der Maas PJ. Demographic and epidemiological determinants of healthcare costs in Netherlands: cost of illness study. BMJ 1998; 317: 111-5.

4. Guez M, Hildingsson C, Nilsson M, Toolanen G. The prevalence of neck pain: a population-based study from northern Sweden. Acta Orthop Scand 2002; 73: 455-9.

5. Hogg-Johnson S, van der Velde G, Carroll LJ, Holm LW, Cassidy JD, Guzman J, et al. The burden and determinants of neck pain in the general population: results of the Bone and Joint Decade 2000-2010 Task Force on Neck Pain and Its Associated Disorders. Spine (Phila Pa 1976) 2008; 33: S39-51.

6. Lau EM, Sham A, Wong KC. The prevalence of and risk factors for neck pain in Hong Kong Chinese. J Public Health Med 1996; 18: 396-9.

7. Hakala P, Rimpelä A, Salminen JJ, Virtanen SM, Rimpelä M. Back, neck, and shoulder pain in Finnish adolescents: national cross sectional surveys. BMJ 2002; 325: 743.

8. Siivola SM, Levoska S, Latvala K, Hoskio E, Vanharanta H, Keinänen-Kiukaanniemi S. Predictive factors for neck and shoulder pain: a longitudinal study in young adults. Spine (Phila Pa 1976) 2004; 29: 1662-9.

9. Fishman SM, Ballantyne JC, Rathmell JP. Bonica's management of pain. 4th ed. Philadelphia, Lippincott Williams \& Wilkins. 2010, pp 1030-4.

10. Kim SA, Park KS, Jang MK, Kam S. Medical facilities utilization according to health status measured by SF-36 in male workers. Korean J Occup Environ Med 2006; 18: 272-83.

11. Jung HJ, Song YM, Kim HY, Chung Jl. Prevalence and associated factors of neck shoulder pain in high school students. J Korean Acad Fam Med 2008; 29: 595-603.

12. Diepenmaat AC, van der Wal MF, de Vet HC, Hirasing RA. Neck/shoulder, low back, and arm pain in relation to computer use, physical activity, stress, and depression among Dutch adolescents. Pediatrics 2006; 117: 412-6.

13. van Gent C, Dols JJ, de Rover CM, Hira Sing RA, de Vet HC. The weight of schoolbags and the occurrence of neck, shoulder, and back pain in young adolescents. Spine (Phila Pa 1976) 2003; 28: 916-21.

14. Croft PR, Lewis M, Papageorgiou AC, Thomas E, Jayson MI, Macfarlane GJ, et al. Risk factors for neck pain: a longitudinal study in the general population. Pain 2001; 93: 317-25.

15. Barnekow-Bergkvist M, Hedberg GE, Janlert U, Jansson E. Determinants of self-reported neck-shoulder and low back symptoms in a general population. Spine (Phila Pa 1976) 1998; 23: 235-43.

16. Bergström $G$, Bodin L, Bertilsson $H$, Jensen $\mathbb{I B}$. Risk factors 
for new episodes of sick leave due to neck or back pain in a working population. A prospective study with an 18month and a three-year follow-up. Occup Environ Med 2007; 64: 279-87.

17. Fredriksson K, Alfredsson L, Köster M, Thorbjörnsson CB, Toomingas $A$, Torgén $M$, et al. Risk factors for neck and upper limb disorders: results from 24 years of follow up. Occup Environ Med 1999; 56: 59-66.

18. Ståhl M, Mikkelsson M, Kautiainen H, Häkkinen A, Ylinen J, Salminen JJ. Neck pain in adolescence. A 4-year follow-up of pain-free preadolescents. Pain 2004; 110: 427-31. 